\title{
Truth is (Still) the Norm for Assertion: A Reply to Littlejohn*
}

\section{Daniel Whiting}

The final and definitive version of this article is to appear in Erkenntnis:

http://link.springer.com/journal/10670. Please refer to the published version.

\section{Introduction}

In a recent paper (Whiting 2013), I defend the view that truth is the fundamental norm for assertion (cf. Weiner 2005). Call this, the Truth View. According to it, the following principle governs the act of asserting:

TN One may assert that $p$ if and only if it is true that $p$.

In defending TN, I reject the view that knowledge is the fundamental norm for assertion. Call this, the Knowledge View (see Williamson 2000). ${ }^{1}$ According to it, the following principle governs the act of asserting:

$\mathrm{KN}$ One may assert that $p$ if and only if one knows that $p$.

In a recent response, Littlejohn (2014) argues that my defence of TN fails and expresses sympathy for the Knowledge View. ${ }^{2}$ Not too long ago, Littlejohn (2012) was a proponent of the Truth View. Whether or not I manage to convince him to rejoin the fold, I hope to show in what follows that his arguments are unsuccessful, in part because they miss their target.

\footnotetext{
* Thanks to the Arts and Humanities Research Council for funding which supported the writing of this paper (AH/K008188/1). Thanks also to Clayton Littlejohn, Conor McHugh, Lee Walters, and an anonymous referee for comments on earlier versions.

${ }^{1}$ The debate concerns the epistemic (broadly-construed) norms for assertion. All parties agree that there are cases in which one may assert a proposition, relative to the relevant epistemic norm, but should not do so, relative to, say, morality or etiquette.

${ }^{2}$ Littlejohn formulates the truth norm as follows: One must not assert that $p$ unless $p$ (i.e., one may assert that $p$ only if $p$ ). It is consistent with this formulation that one may not assert that $p$ (full stop), irrespective of whether it is true or, for that matter, known that $p$.
} 


\section{$2 \quad$ A Defence of the Truth View}

Participants in the debate over the norms of assertion often speak in terms, not of what one may (must, should, etc.) assert, but of when there is warrant for asserting. As I understand the notion, a warrant is a consideration which stands to what one may do as a reason stands to what one ought to do. If Janet ought to go the cinema, there is a reason for her to do so, say, that Psycho is showing; and, if there is a reason for Janet to go to the cinema, and no reason as strong not to go or to do something else, she ought to go. In a similar fashion, if Janet may enter the cinema, there is a warrant for her to do so, say, that she holds a ticket; and, if there is a warrant for Janet to enter the cinema and no reason as strong not to do so, she may enter. ${ }^{3}$

Returning to the issue at hand, the proponent of TN maintains that there is (overall) warrant for Janet to assert, say, that Hitchcock directed Psycho if and only if that is true. ${ }^{4}$ Alternatively, the fact that Hitchcock directed Psycho is a warrant for asserting that he did. The proponent of $\mathrm{KN}$ denies this and maintains that there is warrant for Janet to assert that Hitchcock directed Psycho only if she knows that he did.

Littlejohn provides a neat summary of the kinds of concerns which might lead one to reject $\mathrm{TN}$ in favour of $\mathrm{KN}$ :

Critics of the [Truth View] have argued that TN cannot explain why we don't have warrant to assert various true propositions (e.g., that a losing ticket in an upcoming lottery is a loser, that the number of stars is even (on the assumption that it is), or that the number of stars is even and that we don't know that this is so). They also allege that TN cannot explain why certain

\footnotetext{
${ }^{3}$ Reasons, on this account, are a subset of warrants.

${ }^{4}$ Littlejohn claims that 'the notion of a warrant is not a contributory notion, but an overall one' (2014: 1359). I do not see why we should think this but the issue does not bear on what follows. In the remainder, when I talk of what there is warrant to assert, I mean what there is overall warrant to assert.
} 
challenges are appropriate (e.g., why we shouldn't respond with indifference to the charge that we don't know that what we're saying is true). $(2014: 1355-1356)^{5}$

On behalf of the Truth View, I respond to these concerns in two steps. First, I draw a distinction between there being a reason or warrant for $\varphi$ ing and a person's having that reason or warrant for $\varphi$ ing (Whiting 2013: 856). That Psycho is showing might be a reason for Janet to go to the cinema but, if Janet does not so much as suspect that it is, it cannot be a reason Janet has for going - it cannot be her reason for going. Likewise, that she holds a ticket might be a warrant for Janet to enter the cinema but, if Janet has no idea whether she has a ticket or not, it cannot be a warrant she has for entering.

Second, I argue $^{6}$ that the fact that $p$ is a reason or warrant a subject possesses if and only if she knows that $p$ (see Whiting 2013: $§ 4){ }^{7}$

By appeal to these independently plausible ideas, the proponent of TN can say that there is a warrant for a subject to make an assertion just in case what she asserts is true, but add that the subject has this warrant just in case she knows that it is true. So, if Janet asserts that Hitchcock directed Psycho without knowing that he did, she asserts what there is warrant for asserting but she does not do so with that warrant.

In view of this, the proponent of $\mathrm{TN}$ can agree that there are true propositions which subjects lack the warrant to assert - hence, that subjects would be criticisable for asserting them - even though a warrant for doing so exists. ${ }^{8}$ In addition, she can explain why 'How do you know?' constitutes a challenge to assertion. To say this need not be to query the

\footnotetext{
${ }^{5}$ Critics also argue that truth is not necessary for there to be warrant to assert a proposition (see Lackey 2007). Since Littlejohn and I are concerned with the clash between TN and KN, and since both entail that one may assert that $p$ only if $p$, I shall set this issue aside for another occasion.

${ }^{6}$ Following Hornsby (2008), Hyman (1999), and Unger (1975).

${ }^{7}$ Littlejohn notes that Fantl and McGrath (2009) and Schroeder (2011) argue that one can have that $p$ as a reason for doing something even though one does not know that $p$. That is right. But they do not argue that one can have the fact that $p$ as a reason for doing something if one does not know that $p$. It is the latter claim I rely on in my defence of TN. Since Littlejohn sets this issue aside, I shall do the same.

${ }^{8}$ The background thought here is that, if you ought not to perform a certain act unless some condition obtains, and you perform that act in ignorance of whether the condition obtains, you are in that respect criticisable (e.g., as reckless), even if the relevant condition happens to obtain. There is, of course, more to say here but this is not the part of the account Littlejohn challenges.
} 
existence of a warrant for asserting, but it is to query the possession of such warrant. (For more on all of this, see Whiting 2013: §5.)

\section{$3 \quad$ Mind the Gap}

Littlejohn's critique turns on the following principle:

No Gap One is permitted to $\varphi$ in $C$ if and only if one has a permission to $\varphi$ in $C$. Reformulated in terms of warrants, No Gap is the claim that there is a warrant for a person to $\varphi$ just in case she possesses that warrant. If that is right, one might think, my defence of TN fails. As Littlejohn says:

If No Gap is correct, then one cannot hope to show that knowledge of $p$ 's truth is necessary for having warrant to assert $p$ unless one is prepared to concede that such knowledge is necessary for the existence of the warrant to assert $p$. (2014: 1360)

To concede this is to concede $\mathrm{KN}$.

It is important to stress that Littlejohn is not here challenging, at least not directly, the proponent of TN's account of what it is that warrants assertion, namely, its truth. One might deny this and claim instead that what warrants an assertion is, say, evidence of its truth. A proponent of this view might follow me and distinguish there being warrant (i.e. there being evidence) for an assertion and a person's having that warrant (i.e. having that evidence). Indeed, it is commonplace that there can be evidence which a subject do not possess. What Littlejohn is challenging is specifically the claim that there can be a warrant - irrespective of what provides it - without someone's having it.

Whether No Gap undermines my argument depends on how it is to be understood, in particular, on what it means in this context to say that a subject has a permission (or warrant). According to Littlejohn, 'the right reading of "having" is the reading according to which having a permission is simply a matter of there being a permission that pertains to one' (2014: 1359). So interpreted, No Gap appears to be trivially true. It is equivalent to: 
No Gap* One is permitted to $\varphi$ in $C$ if and only if a permission to $\varphi$ in $C$ pertains to one.

I do not dispute No Gap*. What I deny is that to have a permission in this sense - for a permission to pertain to one - requires knowledge of any sort. The disagreement with Littlejohn concerns whether there can be a permission for one to $\varphi-$ a permission pertaining to one - which one does not have in some other sense. What sense?

On my account, to say that Janet has (in the relevant sense) a reason to go to the cinema is to say that she is in a position to go for, on the basis of, or in light of that reason. Likewise, to say that Janet has (in the relevant sense) a warrant for entering the cinema is to say that she is in a position to do so in light of the warrant for doing so. More generally, a subject has (in the relevant sense) a reason or warrant for $\varphi$ ing if and only if she is in a position to $\varphi$ in light of that reason or warrant (cf. Whiting 2013: 856).

In turn, my claim is that a subject is in a position to $\varphi$ in light of a reason or warrant for doing so just in case she knows the fact which provides that reason or warrant.

Returning to assertion, the view I advance is that Janet might assert that Hitchcock directed Psycho and there might be a warrant (or permission) for her to do so, namely, the fact that Hitchcock directed Psycho, but, unless Janet knows that fact, she cannot assert that Hitchcock directed Psycho in light of the warrant (or permission) there is for doing so.

If talk of having as it figures in No Gap is understood in the way I intend, the principle is equivalent to:

No Gap** There is a permission for one to $\varphi$ in $C$ if and only if one is in a position to $\varphi$ in $C$ in light of that permission.

Presumably, if there is a dispute between Littlejohn and myself, it is not over the meaning of (English) phrases such as 'has a permission'. If it turns out that 'Janet has a permission' just means a permission pertains to Janet, I could drop talk of having a permission and the like, 
and stick to talk of being in a position to act in light of a permission, or just stipulate that 'having a permission' is to be understood in my preferred way in this context. ${ }^{9}$ If there is a genuine dispute between Littlejohn and myself here, it must be that Littlejohn endorses No Gap** while I reject it.

In support of my position, consider again the examples given above. The fact that Psycho is showing might be a reason there is for Janet to go to the cinema - one which might make it the case that she ought to do so - even if Janet is not in a position to go to the cinema in light of that fact, say, because she has not checked the film-listings. Likewise, the fact that Janet holds a ticket for the film might be a warrant for her to enter the cinema - one which might make it the case that she may do so - even if she is not in a position to enter the cinema in light of that fact, say, because she has forgotten she purchased the ticket.

These cases suggest that it is possible for there to be a warrant (permission) for a subject to $\varphi$ though the subject does not have that warrant or permission in the sense I intend. This in turn suggests that No Gap** - hence, No Gap so interpreted - is false.

To bolster this point, suppose that Janet holds a ticket for the film and enters the cinema. Suppose further that Janet does not realise she holds a ticket. In this case, Janet does not enter the cinema in light of the fact that she holds a ticket (or any other fact which warrants doing so). It surely does not follow that Janet may not enter the cinema, hence, that there is no warrant for her to do so. After all, so long as she holds a ticket, the staff at the cinema would not request that she leave simply because she is unaware of this. This case looks like a counterexample to No Gap**.

Consider also advice. ${ }^{10}$ Suppose that Alfred says to Janet, 'You should go to the cinema'. Janet asks why. Alfred replies, 'Psycho is showing'. In this case, it is plausible that

\footnotetext{
${ }^{9}$ As I mention in the original paper, ordinary language, at least at the surface level, cuts across the being/having distinction (2013: 856; cf. Schroeder 2011: 58-59).

${ }^{10}$ Appealing to contexts of advice is a common strategy in arguing for the view that what one ought to do (hence, what one may do) is determined by the facts, as opposed to one's epistemic situation (cf. Thomson 2008:
} 
Alfred is informing Janet of an antecedently existing reason for her to go, rather than bringing that reason into existence, and that, prior to his advice, she was not in a position to go to the cinema in light of that reason. Suppose next that Alfred says to Janet, 'You may enter the cinema'. Janet asks why. Alfred replies, 'You are holding a ticket'. In this case, it is plausible that Alfred is informing Janet of an antecedently existing warrant for her to enter, rather than bringing that warrant into existence, and that, prior to his advice, she was not in a position to enter to the cinema in light of that warrant for doing so. So, contexts of advice suggest that No Gap** is false.

I have offered some considerations in support of my position. What does Littlejohn say against it? He writes:

Compare the case of permission with the case of right. If one has the right to a fair trial, that seems to follow from the fact that there is a right for people in certain circumstances to have a fair trial and the further fact that one finds oneself in those circumstances. It would be outrageous for the authorities to say that there is a right to a fair trial that one would have had if only one's attorney were competent on the matters and put you in a position to know of this right. (2014: 1359-1360)

That would indeed be outrageous. Fortunately, nothing I say supports the authorities.

On my view, that a subject is ignorant of her right to a fair trial, due to an incompetent attorney, makes no difference to whether that right exists or pertains to her, that is, whether she has it in Littlejohn's sense. But it does make a difference to whether she has that right in the sense of being in a position to act in light of it, say, by reminding the authorities that she enjoys it. ${ }^{11}$

187ff). The point here is that contexts of advice support the view that a warrant or reason can exist without a person having that warrant or reason in the relevant sense.

${ }^{11}$ Parallel remarks apply to Littlejohn's discussion of prohibitions (2014: 1360). 
So, Littlejohn's example does not support No Gap**. On the contrary, insofar as it is a case in which there is a right (or permission) which a subject is not in a position to act in light of, it seems to count against that principle.

In summary, if No Gap is to undermine my argument, it must be understood as equivalent to No Gap**. However, so understood, No Gap seems to be false.

\section{$4 \quad$ Further responses}

After presenting his initial argument, Littlejohn acknowledges that the notion of having I appeal to is that of being in a position to act in light of a consideration. And he appears to agree that to have a reason or warrant in this sense requires knowing certain facts (2014: 1362). However, he seems also to think that this does not save my defence of TN. Why? Littlejohn takes my position to be that there is 'more to warranted assertion than simply asserting what there is warrant to assert'. Second, he suggests that the 'more' in question is that the subject assert in light of the fact that there is warrant to do so. So, he takes me to be committed to the following principle:

No Gap*** If $S$ 's assertion that $p$ is warranted, $S$ asserts that $p$ in light of the fact that there is warrant for $S$ to assert that $p$.

Next, Littlejohn argues that No Gap*** is false:

If we knew, say, that there was sufficient warrant for a speaker to assert $p$, I don't think we would say that her assertion was unwarranted simply because she had no view about whether her assertion was warranted. I would think that anyone who was willing to criticize the speaker or her assertion for being unwarranted would think that there was not sufficient warrant for the speaker to assert what she did. (2014: 1363)

In response, I grant that, on my view, there is more to warranted assertion than merely an assertion for which there exists warrant. But the more required is not asserting in light of the (normative) fact that there is warrant for doing so; rather, it is asserting in light of the (non- 
normative) fact which is or provides the warrant for doing so. In the above case, Janet does not make a warranted assertion that Hitchcock directed Psycho unless she does so in light of the fact that he did, which fact warrants her assertion, hence, unless she knows that fact. So, the principle I accept is not No Gap*** but:

No Gap**** If $S$ 's assertion that $p$ is warranted, $S$ asserts that $p$ in light of the fact which warrants asserting that $p$.

According to the proponent of TN, the fact which warrants asserting that $p$ is the fact that $p$.

A version of Littlejohn's objection to No Gap**** does not succeed against this principle. If we know that there is sufficient warrant for Janet to assert that Hitchcock directed Psycho, we might still say that her assertion was unwarranted because she had no view about whether he did this, hence, if she did not know this.

Perhaps there is a sense in which to say that an assertion is warranted is just to say that there exists a warrant for making it, not that it was made in light of that warrant. In that sense, I do not claim that a warranted assertion requires asserting in light of the fact which provides the warrant, hence, knowledge of that fact; it requires only the truth of what is asserted.

\section{$5 \quad$ Moorean Assertions}

Littlejohn raises a further problem which he suggests depends on accepting TN and No Gap***. I think it is independent of the latter. Consider a Moorean proposition:

M It is raining but I do not know that it is raining.

On my view, I cannot have warrant to assert this proposition. If $\mathrm{M}$ is false, there is no warrant to assert it. If $\mathrm{M}$ is true, there is warrant to assert it but I cannot possess that warrant because M is unknowable (Whiting 2013: 860-861). ${ }^{12}$

\footnotetext{
${ }^{12}$ Assuming that, if I know M, I know each of its conjuncts.
} 
Littlejohn objects to this on two counts. First, he thinks that it is counterintuitive even to say that there exists warrant for asserting a proposition like M. I am not sure about this but, in any case, my response to Littlejohn's second point will address the first. He writes:

To my mind, if it is impossible for a speaker to permissibly assert $p$ under such and such circumstances, those circumstances are not circumstances under which there is permission for the speaker to assert $p$. The notion of a permission that cannot possibly be permissibly used strikes me as paradoxical. (2014: 1364)

It is not clear to me that the notion is paradoxical. But, if it is, that suggests that it is a constraint on something's being a permission, and hence a warrant, for someone to $\varphi$ that she is able to $\varphi$ in light of or with that permission or warrant. ${ }^{13}$ If such a constraint holds, one can appeal to it in defence of TN. If I am unable to assert a proposition like M in light of M, there cannot be a warrant for doing so. ${ }^{14}$ As promised, this offers a response to Littlejohn's first point.

\section{Sociology}

In addition to his 'philosophical' objections, Littlejohn makes a 'sociological' point:

The debate about $\mathrm{KN}$ has been a debate about the conditions under which an assertion is warranted. It has not been explicitly a debate about the conditions under which a speaker can assert $p$ in light of the fact that such an assertion is warranted. If [...] Whiting's account is an account of the conditions under which a speaker can assert $p$ in light of the fact that such an assertion is warranted, Whiting's account is [...] not a rival to accounts like KN. (2014: 1362) As I have explained, I am not offering an account of the conditions under which a subject is in a position to make an assertion in light of the fact that it is warranted, but of the conditions

\footnotetext{
${ }^{13}$ As it happens, I float such a constraint in the original article (2013: n32).

${ }^{14}$ Making this move would require revising TN, specifically, restricting it to non-Moorean propositions. But, as discussed, there is an explanation for this restriction.
} 
under which a subject is in a position to make an assertion in light of the fact which warrants doing so. In appealing to that account, am I challenging KN?

Yes. On behalf of the Truth View, I claim that truth warrants assertion. In contrast, the proponent of the Knowledge View claims that only knowledge warrants assertion. These are rival views. In addition, I claim that to have (in the relevant sense) warrant one must know the truth which provides it and that, by appeal to this idea, the proponent of TN can address the challenges which might lead one to hold KN. Moreover, I speculate in the original paper that a failure to distinguish the conditions under which there is warrant for making an assertion from those under which a speaker can assert in light of that warrant lies behind the appeal of KN (Whiting 2013: 863).

\section{$7 \quad$ Conclusion}

I hope to have shown that Littlejohn's arguments against my attempts to defend the Truth View fail. That is, of course, not to deny that those attempts face other problems but the aim of this reply is not to address all possible objections. ${ }^{15}$ For now, it is enough to show that by appeal to the gap between there being a warrant to assert and someone's having that warrant, and what it takes to close that gap, namely, knowledge, one might seek to defend the view that truth is the norm for assertion against one of its main competitors.

\section{References}

Fantl, J. and McGrath, M. 2009: Knowledge in an Uncertain World. Oxford: Oxford University Press.

\footnotetext{
${ }^{15}$ For further critical discussion, see McGlynn 2014: 108-109.
} 
Hornsby, J. 2008: Acting for Reasons: A Disjunctivist Thesis. Disjunctivism: Perception, Action, Knowledge, eds. A. Haddock and F. Macpherson. Oxford: Oxford University Press.

Hyman, J. 1999: How Knowledge Works. Philosophical Quarterly 197: 433-451.

Lackey, J. 2007: Norms of Assertion. Noûs 41: 594-626.

Littlejohn, C. 2012: Justification and the Truth-Connection. Cambridge: Cambridge University Press.

—. 2014: Know Your Rights: On Warranted Assertion and Truth. Erkenntnis 79: 1355-1365.

McGlynn, A. 2014: Knowledge First? Basingstoke: Palgrave.

Schroeder, M. 2011: What Does it Take to 'Have' a Reason? Reasons for Belief, ed. A. Reisner and A. Steglich-Petersen. Cambridge: Cambridge University Press.

Unger, P. 1975: Ignorance. Oxford: Oxford University Press.

Thomson, J. J. 2008: Normativity. Chicago: Open Court.

Weiner, M. 2005: Must We Know What We Say? Philosophical Review 114: 227-251.

Whiting, D. 2013: Stick to the Facts: On the Norms of Assertion. Erkenntnis 78: 847-867.

Williamson, T. 2000: Knowledge and its Limits. Oxford: Oxford University Press. 